\title{
Clinical and immunological outcomes according to adherence to first-line HAART in a urban and rural cohort of HIV-infected patients in Burkina Faso, West Africa
}

Emanuele Focà ${ }^{1,7^{*}}$, Silvia Odolini ${ }^{1}$, Giorgia Sulis ${ }^{1}$, Stefano Calza ${ }^{2}$, Virginio Pietra ${ }^{3,4}$, Paola Rodari ${ }^{1}$, Pier Francesco Giorgetti ${ }^{1}$, Alice Noris ${ }^{1}$, Paul Ouedraogo ${ }^{5}$, Jacques Simpore ${ }^{6}$, Salvatore Pignatelli, ${ }^{3,5}$ and Francesco Castelli ${ }^{1,3}$

\begin{abstract}
Background: Aim of our study is to investigate the clinical and immunological outcomes according to first-line HAART adherence in a large cohort of HIV-infected patients in Burkina Faso.

Methods: A retrospective study was conducted between 2001 and 2009 among patients from two urban medical centers [St. Camille Medical Center (CMSC) and "Pietro Annigoni" Biomolecular Research Center (CERBA)] and 1 in the rural District of Nanoro (St. Camille District Hospital). Socio-demographical and clinical data were analyzed. Adherence was evaluated through a questionnaire investigating 5 key points related to drugs, consultations and blood exams, by assigning 0 to 2 points each up to 10 points overall. Data were collected at baseline and regularly thereafter. Adherence score was considered as a continuous variable and classified in optimal (8-10 points) and sub-optimal (0-7 points). Immunological outcome was evaluated as modification in CD4+ T-cell count over time, while predictors of death were explored by a univariate and multivariate Cox model considering adherence score as a time-varying covariate.
\end{abstract}

Results: A total of 625 patients were included: 455 (72.8\%) were females, the median age was 33.3 (IQR 10.2) years, 204 (32.6.\%) were illiterates, the median CD4+ T-cell count was 149 (IQR 114) cells/ul at baseline. At the end of the observation period we recorded 60/625 deaths and 40 lost to follow-up. The analysis of immunological outcomes showed a significant variation in CD4+ T-cell count between M12 and M24 only for patients with optimal adherence $(\Delta=78.2, p<0.001)$, with a significant $\Delta$ between the two adherence groups at M24 (8-10 vs $0-7, \Delta=53.8, p=0.004)$. Survival multivariate analysis revealed that covariates significantly related to death included being followed at CERBA (urban area) or Nanoro (rural area), and receiving a regimen not including fixed dose combinations, $(p=0.024, p=0.001$ and $p<0.001$ respectively); conversely, an increasing adherence score as well as an optimal adherence score were significantly related to survival $(p<0.001)$.

Conclusions: Adherence to HAART remains pivotal to build up a good therapeutic outcome. Our results confirm that, according to our adherence system evaluation, less adherent patients have a higher risk of death and of inadequate CD4+ count recovery.

Keywords: HIV, Antiretroviral therapy, Adherence, Death, CD4+, Burkina Faso

\footnotetext{
* Correspondence: emanuelefoca@gmail.com

${ }^{1}$ University Division of Infectious and Tropical Diseases, University of Brescia,

Brescia, Italy

${ }^{7}$ University Division of Infectious and Tropical Diseases, University of Brescia,

School of Medicine, P.le Spedali Civili, 1-25123 Brescia, Italy

Full list of author information is available at the end of the article
} 


\section{Background}

It is estimated that about 32.2 million people were living with HIV at the end of 2012. Two thirds of HIV infections (approximately 23.5 million people) were in Sub-Saharan Africa, where a high prevalence of HIV/AIDS is reported (4.7\%) [1]. The introduction of Highly Active Antiretroviral Therapy (HAART) in 1996 has considerably changed the clinical outcomes of infected patients, leading to a dramatic improvement in quality of life and decline in AIDSrelated deaths in low-income Countries [2,3]. By the end of 2012, the number of people receiving antiretroviral therapy reached 9 million, meaning a 20 -fold increase in treatment coverage compared to 2003 [1].

In many low-income Countries, where sometimes neither viral nor immunological parameters are available, adherence monitoring may be an acceptable instrument to estimate HAART effectiveness [4,5]. Besides, secondline regimens are still not easily available in these areas, thus making adherence to a first-line treatment even more important since its failure could leave the patients with no other therapeutic choices. Therefore, some studies have been carried on to better assess adherence patterns in Low and middle-income Countries [6,7] or to correlate adherence with patients outcome [8-11].

WHO usually defines adherence to any treatment as "the extent to which a person's behavior-taking medication, following a diet, and/or executing lifestyle changes, corresponds with agreed recommendations from a healthcare provider". Since no measurement strategy can be considered optimal especially when used alone, an holistic approach is currently suggested [12].

Actually, adherence assessment remains a rather challenging task: direct observation therapy is not practical for HAART regimens that have to be taken lifelong. Methods to establish adherence to antiretroviral treatment include pill count, pharmacy refill records, various self-reporting tools such as questionnaires and visual analogue scales, detection of drug blood levels and electronic monitoring devices [13]. The most commonly applied techniques in low-income Countries are pills count and self reports, though they often overestimate adherence [14].

On the other hand, it was demonstrated that the availability of various types of adherence support may avoid attrition to antiretroviral therapy [15].

Previously conducted studies concerning adherence to antiretrovirals found that a $95 \%$ minimum rate of drug assumption is required in order to guarantee a viroimmunological effectiveness of the therapy [16]. Also in Burkina Faso, the moderate spread of HIV drug resistance strains (from 5 to 15\%) for both nucleoside reverse transcriptase inhibitors (NRTIs) and a non-nucleoside reverse transcriptase inhibitor (NNRTI) among HIVinfected women attending antenatal care, indicates that patients receiving antiretroviral therapy should be adequately supported in order to improve adherence and to avoid a further diffusion of resistance mutations [17].

Aims of this study are to explore death and CD4+ T-cell count evolution according to an original adherence score and to investigate predictors of death in a large cohort of HIV-infected patients over the first 24 months of treatment.

The study presented here was conducted within the European ESTHER (Ensemble pour une Solidarité Thèrapeutique Hopitalière en Reseau) project, a 9-year collaborative experience devoted to give assistance as well as technical and scientific support to fight HIV/AIDS in a low-income Countries.

\section{Methods}

\section{Study design and population}

This is a longitudinal observational single-cohort retrospective study that involved 3 different health facilities in Burkina Faso, 2 located in the suburban area of Ouagadougou [St. Camille Medical Center (CMSC) and "Pietro Annigoni" Biomolecular Research Center (CERBA)] and 1 in the rural District of Nanoro (St. Camille District Hospital). We enrolled all HIV-infected adults who started HAART according to WHO international guidelines available in the study period [18,19], between January 2001 and February 2009. Patients were followed since HAART beginning for at least one year afterwards, two years when feasible.

All data were collected in Burkina Faso (a West-African country with a population of about 13.2 million people) which is among the poorest countries in the world (181st position out of 187) [20]. Notably, in this country only $49 \%$ of the 64000 estimated HAART-needing patients were actually receiving it by the end of 2010 [17].

\section{Data collection}

Consultations and data collection were performed by a medical doctor, available for both scheduled and emergency visits. Routine clinical visits where conducted according to WHO international guidelines [18,19]. Patients enrolled in the study, were evaluated at baseline $\left(D_{0}\right)$, on day $15\left(D_{15}\right)$, each month during the first semester $\left(\mathrm{M}_{1}-\mathrm{M}_{6}\right)$ and thereafter every three months since HAART initiation. Each time, WHO clinical stage and adherence score (from $\mathrm{D}_{15}$ on) were registered. Furthermore, CD4+ T cell count was scheduled on $D_{0}$ and then at $M_{6}, M_{12}$ and $\mathrm{M}_{24}$, together with some routine laboratory tests (i.e. blood cell count, transaminases, creatinine, amylasemia and glycaemia). During the study, patients were categorized into (i) followed, (ii) lost to follow-up, (iii) dead and (iv) referred to other Medical Centers. A patient was considered lost to follow up if he/she had missed 2 consecutive visits without a further contact. Demographical and clinical variables, 
social behaviors, family conditions and literacy were also analyzed.

\section{Adherence score}

Adherence was assessed through the administration of a questionnaire regarding 5 different aspects: (1) pills count, (2) delays and omissions in taking pills referred from patient, (3) knowledge of posology, (4) punctuality on consultations, (5) proper execution of blood tests as planned at the previous consultation. A score was estimated by the medical doctor who performed the visit through the assignment of 0 (i.e. unreached goal), 1 (i.e. partially reached goal) or 2 (i.e. fully reached goal) points to each feature, up to 10 points overall. This score has not been validated. Treatment interruption was determined as a referred and/or planned history of stopping and resuming treatment, and corresponds to a zero score. On the other hand, a full adherence score was attributed to patients (1) who took at least $95 \%$ of pills (as stated through direct count and self report of missed doses), (2) at the right time of the day (with 30 minutes tolerance), (3) who properly knew the regimen posology, (4) presented on scheduled consultations ( \pm 2 days, since extra-medications were provided) and (5) underwent blood tests as planned. If a patient was lost to follow up (see above), no value was assigned to the adherence score, and the patient was considered in the statistical analysis only according to the period of follow-up.

\section{Statistical analysis}

Associations between categorical variables were evaluated using Chi-square tests or Fisher exact tests where needed. Overall survival was modeled using Cox models considering adherence score as time-varying covariate. The following variables were considered in univariate analyses: center, age (continuous), gender, religion, living area, HIV type infection, literacy, CD4+ T-cell count, WHO clinical stage, HAART regimen including fixed dose combination (FDC), calendar year and adherence score (as continuous and categorical $[0-7,8-10]$ variable) and those significant were included in a multivariate Cox model. Model selection for the multivariate Cox model was based on likelihood ratio tests. The final model included center, HAART regimen including FDC, calendar year, WHO clinical stage and adherence score (as continuous and categorical [0-7,8-10] variable). Both calendar year and WHO clinical stage were included as a stratification variable. When performing the survival analysis, all patients lost to follow-up were censored.

CD4+ T-cell count variation over time was modeled using a random-intercept linear mixed model [21] with CD4+ T-cell expressed on the squared root scale. Model selection was performed based on likelihood ratio tests both for fixed and random effects of the model. Within- subjects errors were auto-correlation was modeled using a continuous first-order autoregressive process (CAR1) with an estimated autocorrelation coefficient of 0.66 . The final model included sex, age (continuous), center, WHO HIV clinical stage, HAART regimen including FDC, baseline CD4+ T-cell count, adherence score (categorized as [0-7,8-10]), HIV type infection (HIV-1, HIV2 or HIV 1 and 2 mixed) as well as HAART regimen including FDC-time and score-time interaction terms.

Considering the possibility of a missing not at random pattern and its potential effects on model estimates we conducted a sensitivity analysis fitting a linear mixed model as specified above only on subjects that had a visit at 24 months. Results did not differ from the model with all data (data not shown).

All analysis were performed using the $\mathrm{R}$ statistical software [22] and specifically the packages survival [23] and nlme [24]. All statistical tests were performed based on a significance level of $5 \%$.

\section{Ethics}

The Study was conducted in compliance with the Helsinki declaration. The Joint Centre Médicale Saint Camille and Centre de Recherche Biomoléculaire Pietro Annigoni Ethics Committee were duly informed about the ongoing research and gave their permission. In fact, the CNERS (Comité National d'éthique pour la Recherche en Santé) is questioned only in case of interventional clinical trials as well as in international or national pharmacological studies: therefore in this case it was not informed. Moreover, being a retrospective non-interventional study founded on post hoc analysis of data already present in patients' files, and collected only for clinical indications, no written informed consent was asked to patients.

\section{Results \\ Patients characteristics}

A total of $625 \mathrm{HIV}$-infected patients who started HAART between January 2001 and February 2009, were included. Socio-demographic and clinical features of this cohort are showed in Tables 1 and 2 respectively. Patients were followed for a median time of 20.8 months (min. $0.6-\max 24$ months). Most individuals were female $(455 / 625,72.8 \%)$ and the median age at enrollment was 33.3 (IQR 10.2) years. Moreover, a large proportion of patients had a stable partner (59.3\%), many were widowed $(23.0 \%)$ and $17.1 \%$ had no stable partner. With respect to literacy, $32.6 \%(204 / 625)$ of patients were illiterate. Notably, only $57.8 \%$ of enrolled subjects spoke French, nearly all the others knew local dialects only. The $74.6 \%(466 / 625)$ of patients were living in Ouagadougou, while the remaining $25.4 \%$ (159/625) were from rural areas. 
Table 1 Socio-demographic characteristics of patients at baseline

\begin{tabular}{lc}
\hline Variable & All patients $(\mathbf{n}=\mathbf{6 2 5})$ \\
\hline Sex & \\
-Female & $455 / 625(72.8)$ \\
-Male & $160 / 625(27.2)$ \\
Median age at baseline &
\end{tabular}

Years [median (IQR)]

$33.3(10.2)$

Religion

-Christian

$368 / 625(58.9)$

-Muslim

-Animist

275/625 (40.8)

2/625 (0.3)

\section{Spoken language}

-French

$361 / 625(57.8)$

-Only local dialects

-Missing data

\section{Literacy}

-Illiterate

-Literate

Living area

-Urban

-Rural

\section{Calendar year of enrolment}

in the whole cohort

$-\leq 2003$
-2004
-2005
-2006
-2007
-2008

\section{Marital status}

-Stable partner

-No stable partner

-Widowed

-Missing data

Pregnancy at baseline

$$
\text { -Yes }
$$

-No

-Missing data

HIV-infected partner

$$
\text { -Yes }
$$

- No

-Missing data
$27 / 625(4.3)$

204/625 (32.6)

$421 / 625(67.4)$

$466 / 625(74.6)$

$159 / 625(25.4)$

$$
\begin{aligned}
& 71 / 625(11.4) \\
& 166 / 625(26.6) \\
& 130 / 625(20.8) \\
& 78 / 625(12.5) \\
& 111 / 625(17.8) \\
& 69 / 625(11)
\end{aligned}
$$

$371 / 625$ (59.3)

$107 / 625$ (17.1)

144/625 (23.0)

$3 / 625(0.5)$

$73 / 455$ (16.1)

$381 / 455(83.7)$

$1 / 455(0.2)$

199/408 (48.8)

$82 / 408(20.1)$

$127 / 408(31.1)$
$237 / 625(37.9)$
Table 1 Socio-demographic characteristics of patients at baseline (Continued)

\begin{tabular}{lc}
\hline Status at the end of follow-up & \\
-Followed & $488 / 625(78.1)$ \\
-Lost to follow-up & $40 / 625(6.4)$ \\
-Dead & $60 / 625(9.6)$ \\
-Referred & $37 / 625(5.9)$ \\
\hline Notes: IQR: Interquartile range. All values are expressed as N (\%).
\end{tabular}

At the beginning of antiretroviral treatment, a significant proportion of patients belonged to an advanced WHO clinical stage $(50.6 \%, 316 / 625)$ and the median CD4+ absolute count was 149 cells/ $\mu$ l (IQR 114). Overall, 63/625 patients $(10.1 \%)$ had a concurrent HBV or HCV chronic infection. The $87.8 \%(549 / 625)$ of prescribed HAART regimens consisted of two nucleoside reverse transcriptase inhibitors (NRTIs) and a non-nucleoside reverse transcriptase inhibitor (NNRTI), while the remaining 12.2\%

\begin{tabular}{|c|c|}
\hline Variable & All patients $(N=625)$ \\
\hline \multicolumn{2}{|c|}{$\begin{array}{l}\text { Median CD4+ T cell count at } \\
\text { baseline }(c e l l s / \mu \mathrm{l})\end{array}$} \\
\hline cells/pl [median (IQR)] & 149 (114) \\
\hline \multicolumn{2}{|l|}{ [calculated on 593/625 pts] } \\
\hline \multicolumn{2}{|c|}{ CD4 T cell count at baseline } \\
\hline$-<50$ cells $/ \mu \mathrm{l}$ & $88 / 593(14.8)$ \\
\hline$->50$ cells $/ \mu \mathrm{l}$ & $505 / 593(85.2)$ \\
\hline \multicolumn{2}{|l|}{ HIV-type infection } \\
\hline$-H I V-1$ & $587 / 625(93.9)$ \\
\hline$-H I V-2$ & 10/625 (1.6) \\
\hline$-H I V-1+H I V-2$ & $28 / 625(4.5)$ \\
\hline \multicolumn{2}{|c|}{ WHO clinical stage at baseline } \\
\hline -Early (stage 1 and 2) & $309 / 625(49.4)$ \\
\hline -Advanced (3 and 4) & $316 / 625(50.6)$ \\
\hline \multicolumn{2}{|l|}{ HAART regimen } \\
\hline$-2 N R T I S+1 N N R T I$ & $549 / 625(87.8)$ \\
\hline$-2 \mathrm{NRTIS}+1 \mathrm{PI} / \mathrm{r}$ & $76 / 625(12.2)$ \\
\hline \multicolumn{2}{|c|}{ HAART regimen including FDC } \\
\hline -Yes & $474 / 625(75.8)$ \\
\hline$-\mathrm{No}$ & $151 / 625(24.2)$ \\
\hline
\end{tabular}
$(76 / 625)$ were made up of two NRTIs and a protease inhibitor (PI). Moreover, 75.8\% (474/625) of patients received FDC (e.g. Zidovudine/Lamivudine, Stavudine/ Lamivudine/Nevirapine, Stavudine/Lamivudine).

By the end of follow-up, 9.6\% of patients $(60 / 625)$ had died, 5.9\% (37/625) had been referred, 6.4\% (40/625)

Table 2 Clinical characteristics of patients at baseline 
were lost to follow-up and 78.1\% (487/625) were still under active monitoring. Median follow-up for subject censored before the end of the study ( 24 months) was 8.97 months, in particular median follow-up for dead patients was 6.54 months.

\section{CD4+ T cell count increase according to adherence score}

To evaluate the immunological outcome, we considered two different groups of patients based on adherence score considered at each time-point. We divided patients with optimal adherence (8-10 points) from those with sub-optimal adherence (0-7 points). We observed a significant increase in CD4+ T-cell count from baseline to M6, both in the 0-7 $(\Delta=112.4, \mathrm{p}<$ $0.001)$ and $8-10$ groups $(\Delta=120.7, \mathrm{p}<0.001)$, while the difference between the two groups at M6 was not significant $(p=0.56)$. Moreover, from M6 to M12 we found a CD4+ T-cell count significant variation in both adherence groups $(\Delta=62.6 \mathrm{p}<0.001$ and $\Delta=38.1 \mathrm{p}<$ 0.001 in the $0-7$ and $8-10$ group respectively), and a non-significant difference was observed between the two groups at M12 ( $\mathrm{p}=0.39)$. A significant variation was observed between M12 and M24 only in the 8-10 group $(\Delta=78.2, \mathrm{p}<0.001)$ with a significant $\Delta$ between the two groups at M24 (8-10 vs $0-7, \Delta=53.8, \mathrm{p}=0.004)$. Figure 1 shows the estimated $\Delta$ (from G0) and their standard errors.

\section{Survival and predictors}

Univariate and multivariate logistic regression analysis were conducted to explore the possible predictors of death as summarized in Table 3. In univariate analysis factor independently associated with death were: being followed at CERBA or Nanoro ( $p<0.001$ for both

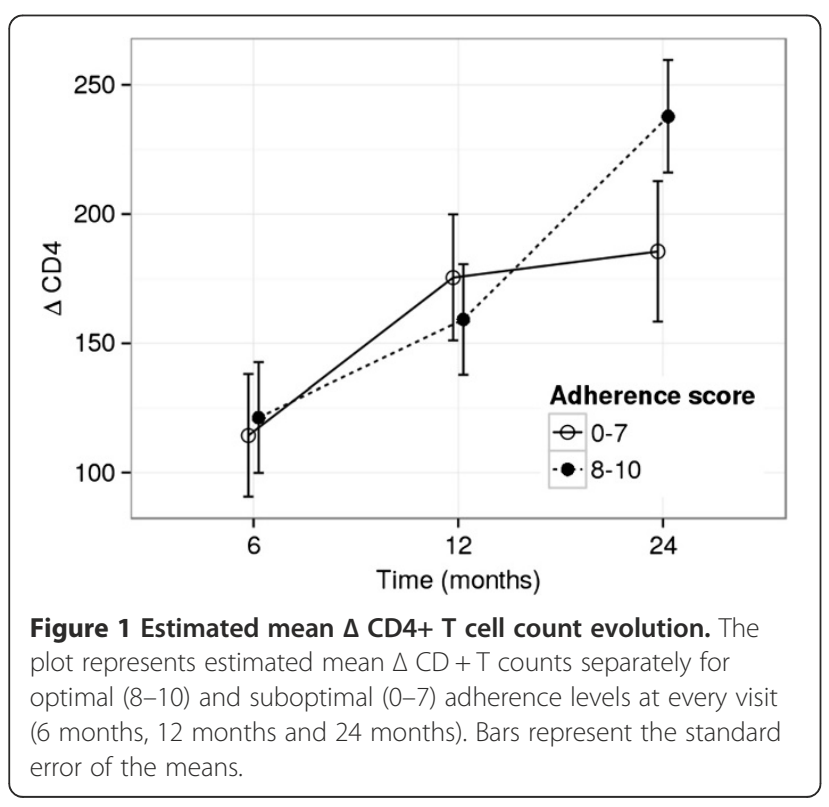

variables), living in rural area, increasing age, early HIV disease clinical stage and receiving a HAART regimen not including FDCs $(\mathrm{p}=0.008, \mathrm{p}=0.076, \mathrm{p}=$ 0.013 and $\mathrm{p}<0.001$ respectively). Besides, factors inversely related to death were increasing adherence score (for 1point increase) and optimal adherence score (8-10 point), both considered as time-varying covariates $(\mathrm{p}<0.001$ and $\mathrm{p}<0.001$ respectively). In the multivariate model covariates significantly associated with death included being followed at CERBA or Nanoro and receiving a regimen not including FDCs, $(\mathrm{p}=0.024, \mathrm{p}=0.001$ and $\mathrm{p}<0.001$ respectively); the increasing adherence score and the optimal adherence score (8-10 points) were confirmed to be significantly related to survival ( $\mathrm{p}<0.001$ for both).

\section{Discussion}

In this study we observed a direct correlation between the two different outcomes (survival and CD4+ T-cell count recovery) and adherence evaluated through our score: our data substantially confirm previous findings $[25,26]$ suggesting that good adherence enhances CD4+ T-cell recovery and decreases mortality.

A significant proportion of our study population was represented by women (72.8\%), since CMSC is a medical center devoted to "mother and child health-care" where patients are predominantly pregnant women and their HIV-infected partners [27]. Hence, patients who went to CMSC were usually asymptomatic at enrolment (i.e. at an early WHO clinical stage at baseline). Conversely, the other two centers mainly admit symptomatic individuals and hospitalized late presenters.

Moreover, people coming from Nanoro rural District often emigrate particularly to Ivory Coast, delaying access to HIV screening and care [28]. The high proportion of HIV-infected migrants on HAART who work abroad may be partly responsible for the worsening of therapeutic adherence in this setting. This phenomenon was taken into account during the statistical analysis and the multivariate logistic regression model was realized after stratifying for WHO clinical stage at baseline and for calendar year.

The lack of a gold standard method to evaluate adherence brought us to use a multi-parametric strategy based on a combination of questionnaires, pills count, punctuality on clinical consultations and blood tests. This method allowed us to bypass single measurements-related biases, by taking into account several aspects of treatment adherence according to WHO recommendations [12]. Previous studies employed a variety of methods to assess adherence, with different thresholds to define good adherence, and a wide range of adherent patients proportions were reported (from 20.7 to $93.5 \%$ ) $[10,11,29-34]$. Since the methodologies of these studies widely varied from each other, they are not easily comparable to our research. 
Table 3 Predictors of death: univariate and multivariate analysis

\begin{tabular}{|c|c|c|c|c|c|c|c|}
\hline & \multirow[b]{2}{*}{ Variables } & \multicolumn{3}{|c|}{ Univariate analysis } & \multicolumn{3}{|c|}{ Multivariate analysis } \\
\hline & & $\mathrm{HR}$ & $95 \%$ IC & $p$ value & HR & $95 \%$ IC & $p$ value \\
\hline \multirow[t]{2}{*}{ Center } & CERBA vs CMSC & 4.98 & $2.19-11.32$ & $<0.001$ & 2.76 & $1.15-6.65$ & 0.024 \\
\hline & Nanoro vs CMSC & 8.08 & $3.35-19.49$ & $<0.001$ & 10.60 & $3.78-29.75$ & 0.001 \\
\hline Sex & $M$ vs $F$ & 1.44 & $0.83-2.51$ & 0.21 & & & \\
\hline Religion & Muslim vs Christian & 0.90 & $0.52-1.54$ & 0.69 & & & \\
\hline Living area & Rural vs Urban. & 2.12 & $1.24-3.64$ & 0.008 & - & - & - \\
\hline \multirow[t]{2}{*}{ HIV type infection } & 2 vs 1 & 1.29 & $0.18-9.38$ & 0.80 & & & \\
\hline & Mixed vs 1 & 2.31 & $0.92-5.78$ & 0.075 & & & \\
\hline Literacy & Illiterate vs literate & 1.29 & $0.75-2.23$ & 0.36 & & & \\
\hline Age & 1 year increase & 1.32 & $0.98-1.79$ & 0.076 & & & \\
\hline CD4+ T-cell count at baseline & $\leq 50$ vs $>50$ & 1.53 & $0.74-3.17$ & 0.28 & & & \\
\hline WHO HIV clinical stage ${ }^{\$}$ & Early vs advanced & 0.5 & $0.29-0.88$ & 0.016 & - & - & - \\
\hline HAART regimen including FDC & No vs Yes & 2.70 & $1.58-4.59$ & $<0.001$ & 0.40 & $0.22-0.70$ & $<0.001$ \\
\hline \multirow[t]{2}{*}{ Increasing adherence score } & For 1 point increasing & 0.60 & $0.47-0.76$ & $<0.001$ & 0.87 & $0.81-0.93$ & $<0.001$ \\
\hline & $8-10$ vs $0-7$ & 0.37 & $0.21-0.63$ & $<0.001$ & 0.32 & $0.18-0.57$ & $<0.001$ \\
\hline Calendar year*\$ & - & - & - & 0.008 & - & - & - \\
\hline
\end{tabular}

Notes: HR: hazard ratio; Cl: confidence interval; CERBA: "Pietro Annigoni” Biomolecular Research Center; CMSC: Centre Médicale Saint Camille, Ougadougou; HAART: highly active antiretroviral therapy; FDC: fixed dose combination.

*For Calendar Year only p-value for likelihood-ratio test (model with/without variable) reported.

\$Variables included in the model as strata.

${ }^{\S}$ p-values below 0.05 (in boldface) were considered to be significant.

The increase in CD4+ T-cell count was similar in patients with optimal and suboptimal adherence $(0-7$ and $8-10$ group) during the first year of follow-up, while a better adherence (8-10 group) during the second year was significantly related to a progressive increase in CD4+ Tcell count. Our findings are in line with those described in the DART trial where investigators observed a worse immunological recovery (assessed through the CD4+ T-cell count evolution) among less-adherent patients.

We also found that good adherence is strongly related to a lower risk of death in univariate and multivariate models, given that the adherence score was considered as continuous variable or as a binomial variable $(8-10 \mathrm{vs}$ 0-7 points).

The univariate analysis of death predictors revealed that living in urban areas was associated to a better survival, while the other socio-demographic features (education, religion, gender and increasing age) were not. In fact, living in a urban area is likely to be associated with fewer disruptions in access to medicines, which seem to facilitate adherence [35-37]. Moreover, WHO clinical stage at baseline resulted to be significantly related to death, while CD4+ T-cell count $(<50 v s>50$ cells/ $\mu$ l) did not.

The multivariate analysis showed an increased risk of death among patients who were followed at CERBA or Nanoro as compared to those followed at CMSC, as a consequence of the above-mentioned differences between patients enrolled in the three healthcare facilities.
In addition, receiving a regimen including FDCs was confirmed to be significantly related to survival, suggesting the importance of a wider access to HAART in lowincome Countries with a particular attention to compact regimens [38].

At any rate, some limitations should b e taken into consideration while interpreting our study. First of all, it was not possible to collect full data for the whole cohort since medical records were sometimes incomplete or because patients had died, had been lost to follow-up or transferred elsewhere. Second, our adherence score has not been validated and we are not able to establish the relative weight of each component of the score. Moreover, we did not compare this score with other methods to evaluate adherence since validation of this score was not the aim of this study. Lastly, the assignation of our score is purely at the discretion of the physician who performed the visit, and it should not be interpreted as a objective measure. Although the scores assigned at each visit were equally weighted, despite the variability in the length of assessment, the patients were followed in accordance with current WHO guidelines and all data were analyzed only retrospectively.

\section{Conclusions}

In summary, our findings confirm that optimal adherence is strongly related to better immunological recovery and survival, though assessed through a non-validated score. 
Our results reinforce the need of additional support such as reminders and enhanced community education [38]. In fact, HIV/AIDS - related stigma still represents a major concern in low-income Countries especially in SubSaharan Africa and it is thought to significantly influence patients' compliance. Notably, scaling up antiretroviral treatment coverage alone is not sufficient: adherence improvement remains necessary, with a particular attention to prescribe FDC-containing regimens in order to achieve both clinical and immunological outcomes.

\section{Competing interests}

EF have received travel grants or speakers honoraria from several Pharmaceuticals Companies producing antiretroviral drugs and consultancy fees from Gilead and Abbvie but this did not influence the content of this paper. FC is acting as Principal Investigator in investigational Clinical Trials sponsored by Pharmaceuticals Companies producing antiretroviral drugs. The remaining authors declare that they have no competing interests.

\section{Authors' contributions}

Study concept and design: EF, SO, VP. Acquisition of data: EF, SO, AN. Analysis and interpretation of data: EF, SO, GS, SC, VP. Drafting of the manuscript: EF, SO, GS, PFG. Statistical Analysis: SC. Critical revision of the manuscript for important intellectual content: EF, SO, GS, SC, VP, PR, PFG, AN, $\mathrm{PO}, \mathrm{JS}, \mathrm{SP}, \mathrm{FC}$. All authors read and approved the final manuscript.

\section{Acknowledgements}

The Authors would like to thank the ESTHER Project-Italy funded by Istituto Superiore di Sanità, Rome, Italy. The Authors thank all physicians and medical students who participated to "ESTHER project" - Brescia in Burkina Faso. A special thank to the Camillian Vice-Province in Burkina Faso and the technical-scientific support assured by the University of Brescia, the University of Ouagadougou and the NGO Medicus Mundi Italy. This work was partially supported by NEAT (Network for Excellence in Antiretroviral Treatment) funded by the European Commission (Project number: LSHP-CT-2006-037570).

\section{Author details}

'University Division of Infectious and Tropical Diseases, University of Brescia, Brescia, Italy. ${ }^{2}$ Unit of Biostatistics and Biomatemathics, Department of Molecular and Translational Medicine, University of Brescia, Brescia, Italy. ${ }^{3}$ Medicus Mundi Italy NGO, Brescia, Italy. ${ }^{4}$ Saint Camille District Hospital, Nanoro, Burkina Faso. ${ }^{5}$ Centre Medicale Saint Camille (CMSC), Ouagadougou, Burkina Faso. ${ }^{6}$ Centre de Recherché Biomoleculaire Pietro Annigoni, Ouagadougou, Burkina Faso. ${ }^{7}$ University Division of Infectious and Tropical Diseases, University of Brescia, School of Medicine, P.le Spedali Civili, 1-25123 Brescia, Italy.

Received: 6 June 2013 Accepted: 12 March 2014

Published: 21 March 2014

\section{References}

1. WHO/UNAIDS: Global Report: UNAIDS Report on the Global AIDS Epidemic. 2013. http://www.unaids.org/en/media/unaids/contentassets/documents/ epidemiology/2013/gr2013/UNAIDS_Global_Report_2013_en.pdf.

2. Palella FJ Jr, Delaney KM, Moorman AC, Loveless MO, Fuhrer J, Satten GA, Aschman DJ, Holmberg SD: Declining morbidity and mortality among patients with advanced human immunodeficiency virus infection. $N$ Engl J Med 1998, 338(13):853-860.

3. Borrell C, Rodríguez-Sanz M, Pasarín MI, Brugal MT, García-de-Olalla P, Marí-Dell'Olmo M, Caylà J: AIDS mortality before and after the introduction of highly active antiretroviral therapy: does it vary with socioeconomic group in a country with a National Health System? Eur $J$ Public Health 2006, 16(6):601-608.

4. Ammassari A, Trotta MP, Murri R, Castelli F, Narciso P, Noto P, Vecchiet J, D'Arminio Monforte A, Wu AW, Antinori A, AdICoNA Study Group: Correlates and predictors of adherence to highly active antiretroviral therapy: overview of published literature. J Acquir Immune Defic Syndr 2002, 31(Suppl 3):S123-S127.

5. Grossberg R, Zhang $Y$, Gross R: A time-to-prescription-refill measure of antiretroviral adherence predicted changes in viral load in HIV. J Clin Epidemiol 2004, 57(10):1107-1110.

6. Berg KM, Arnsten JH: Practical and conceptual challenges in measuring antiretroviral adherence. J Acquir Immune Defic Syndr 2006, 43(Suppl 1):S79-S87.

7. Hanif H, Bastos Fl, Malta M, Bertoni N, Surkan PJ, Winch PJ, Kerrigan D: Individual and contextual factors of influence on adherence to antiretrovirals among people attending public clinics in Rio de Janeiro, Brazil. BMC Public Health 2013, 13:574-583.

8. Mendelsohn JB, Schilperoord M, Spiegel P, Ross DA: Adherence to antiretroviral therapy and treatment outcomes among conflict-affected and forcibly displaced populations: a systematic review. Confl Health 2012, 6(1):9.

9. Kiwuwa-Muyingo S, Oja H, Walker AS, IImonen P, Levin J, Mambule I, Reid A, Mugyenyi $P$, Todd J: Dynamic logistic regression model and population attributable fraction to investigate the association between adherence, missed visits and mortality: a study of HIV-infected adults surviving the first year of ART. BMC Infect Dis 2013, 13:395-409.

10. Simpson SH, Eurich DT, Majumdar SR, Padwal RS, Tsuyuki RT, Varney J, Johnson JA: A meta-analysis of the association between adherence to drug therapy and mortality. BMJ 2006, 333:7557-7562

11. Kiwuwa-Muyingo S, Walker AS, Oja H, Levin J, Miiro G, Katabira E, Kityo C, Hakim J, Todd J: The impact of first year adherence to antiretroviral therapy on long-term clinical and immunological outcomes in the DART trial in Uganda and Zimbabwe. Trop Med Int Health 2012, 17:584-594.

12. World Health Organization: Adherence to Long-Term Therapies. Evidence for Action. Geneva, Switzerland: WHO; 2003.

13. Unge C, Södergård B, Marrone G, Thorson A, Lukhwaro A, Carter J, llako F, Ekström AM: Long-term adherence to antiretroviral treatment and program drop-out in a high-risk urban setting in sub-Saharan Africa: a prospective cohort study. PLoS One 2010, 5(10):e13613.

14. Liu H, Golin CE, Miller LG, Hays RD, Beck CK, Sanandaji S, Christian J, Maldonado T, Duran D, Kaplan AH, Wenger NS: A comparison study of multiple measures of adherence to HIV protease inhibitors. Ann Intern Med 2001, 134(10):968-977.

15. Lamb MR, El-Sadr WM, Geng E, Nash D: Association of adherence support and outreach services with total attrition, loss to follow-up, and death among ART patients in sub-Saharan Africa. PLoS One 2012, 7(6):e38443.

16. Paterson DL, Swindells S, Mohr J, Brester M, Vergis EN, Squier C, Wagener $\mathrm{MM}$, Singh N: Adherence to protease inhibitor therapy and outcomes in patients with HIV infection. Ann Intern Med 2000, 133(1):21-30.

17. World Health Organization/UNAIDS/UNICEF: Global HIV/AIDS response. Epidemic update and health sector progress towards universal access. Progress report 2011. http://whqlibdoc.who.int/publications/2011/ 9789241502986_eng.pdf.

18. World Health Organization: Scaling up antiretroviral therapy in resource limited settings: treatment guidelines for a public health approach, 2003 revision. 2004. WHO, Geneva. http://www.who.int/hiv/pub/prev_care/en/ arvrevision2003en.pdf.

19. World Health Organization: Antiretroviral therapy for HIV infection in adults and adolescents. Recommendations for a public health approach, 2006 revision. 2006. WHO, Geneva. http://www.who.int/hiv/pub/ guidelines/artadultguidelines.pdf.

20. United Nations Development Programme (UNDP): Human development report 2011. Sustainability and equity: a better future for all. 2011. UNDP, New York. http://hdr.undp.org/en/media/HDR_2011_EN_Complete.pdf.

21. Verbeke G, Molenberghs G: Linear Mixed Models for Longitudinal Data; 2009 Springer, ISBN-13:978-1441902993.

22. R Core Team: R: A language and environment for statistical computing. 2013. R Foundation for Statistical Computing, Vienna, Austria. URL [http:// www.R-project.org/]

23. Therneau T: A Package for Survival Analysis in S. R package version 2.37-7; 2014. http://CRAN.R-project.org/package=survival.

24. Pinheiro J, Bates D, DebRoy S, Sarkar D, R Development Core Team: $n / m e$ : Linear and Nonlinear Mixed Effects Models. R package version 3.1-115; 2014. http://CRAN.R-project.org/package $=$ nlme.

25. Wools-Kaloustian K, Kimaiyo S, Diero L, Siika A, Sidle J, Yiannoutsos CT, Musick B, Einterz R, Fife KH, Tierney WM: Viability and effectiveness of 
large-scale HIV treatment initiatives in sub-Saharan Africa: experience from western Kenya. AIDS 2006, 20(1):41-48.

26. Abrogoua DP, Kablan BJ, Kamenan BA, Aulagner G, N'guessan K, Zohoré C: Assessment of the impact of adherence and other predictors during HAART on various CD4 cell responses in resource-limited settings. Patient Prefer Adherence 2012, 6:227-237.

27. Pignatelli S, Simpore J, Pietra V, Ouedraogo L, Conombo G, Saleri N, Pizzocolo C, De laco G, Tall F, Ouiminga A, Carosi G, Castelli F: Factors predicting uptake of voluntary counselling and testing in a real-life setting in a mother-and-child center in Ouagadougou, Burkina Faso. Trop Med Int Health 2006, 11(3):350-357.

28. Autino B, Odolini $S$, Nitiema H, Kiema D, Melzani A, Pietra V, Martinetto M, Bettinzoli M, Simpore J, Sulis G, Focà E, Castelli F: [HIV/AIDS care and international migrations in the rural district of Nanoro, Burkina Faso]. Bull Soc Pathol Exot 2012, 105(2):130-136.

29. Karcher H, Omondi A, Odera J, Kunz A, Harms G: Risk factors for treatment denial and loss to follow-up in an antiretroviral treatment cohort in Kenya. Trop Med Int Health 2007, 12(5):687-694.

30. Etard JF, Lanièce I, Fall MB, Cilote V, Blazejewski L, Diop K, Desclaux A Ecochard R, Ndoye I, Delaporte E, ANRS 1215/1290 Study Group: A 84month follow up of adherence to HAART in a cohort of adult Senegalese patients. Trop Med Int Health 2007, 12(10):1191-1198.

31. Pearson CR, Micek MA, Simoni JM, Hoff PD, Matediana E, Martin DP, Gloyd SS: Randomized control trial of peer-delivered, modified directly observed therapy for HAART in Mozambique. J Acquir Immune Defic Syndr 2007, 46(2):238-244.

32. Marazzi MC, Bartolo M, Emberti Gialloreti L, Germano P, Guidotti G, Liotta G, Magnano San Lio M, Mancinelli S, Modolo MA, Narciso P, Perno CF,

Scarcella P, Tintisona G, Palombi L: Improving adherence to highly active anti-retroviral therapy in Africa: the DREAM programme in Mozambique. Health Educ Res 2006, 21(1):34-42.

33. Nachega JB, Stein DM, Lehman DA, Hlatshwayo D, Mothopeng R, Chaisson RE, Karstaedt AS: Adherence to antiretroviral therapy in HIV-infected adults in Soweto, South Africa. AIDS Res Hum Retroviruses 2004, 20(10):1053-1056.

34. Bajunirwe F, Arts EJ, Tisch DJ, King CH, Debanne SM, Sethi AK: Adherence and treatment response among HIV-1-infected adults receiving antiretroviral therapy in a rural government hospital in Southwestern Uganda. J Int Assoc Physicians AIDS Care (Chic) 2009, 8(2):139-147.

35. Kip E, Ehlers VJ, van der Wal DM: Patients' adherence to anti-retroviral therapy in Botswana. J Nurs Scholarsh 2009, 41(2):149-157.

36. Sanjobo N, Frich JC, Fretheim A: Barriers and facilitators to patients' adherence to antiretroviral treatment in Zambia: a qualitative study. SAHARA J 2008, 5(3):136-143.

37. Peltzer K, Friend-du Preez N, Ramlagan S, Anderson J: Antiretroviral treatment adherence among HIV patients in KwaZulu-Natal, South Africa. BMC Public Health 2010, 10:111.

38. Castelli F, Pietra V, Diallo I, Schumacher RF, Simpore J: Antiretroviral (ARV) therapy in resource poor countries: what do we need in real life? Open AIDS J 2010, 4:28-32.

doi:10.1186/1471-2334-14-153

Cite this article as: Focà et al:: Clinical and immunological outcomes according to adherence to first-line HAART in a urban and rural cohort of HIV-infected patients in Burkina Faso, West Africa. BMC Infectious Diseases 2014 14:153.

\section{Submit your next manuscript to BioMed Central and take full advantage of:}

- Convenient online submission

- Thorough peer review

- No space constraints or color figure charges

- Immediate publication on acceptance

- Inclusion in PubMed, CAS, Scopus and Google Scholar

- Research which is freely available for redistribution 